\title{
Lateral one-third gland resection in Cushing patients with failed adenoma identification leads to low remission rates: long-term observations from a small, single-center cohort
}

\author{
Lukas Andereggen $^{1,2}$ (D) $\cdot$ Luigi Mariani $^{3} \cdot$ Jürgen Beck $^{4} \cdot$ Robert H. Andres $^{1} \cdot$ Jan Gralla $^{5} \cdot$ Markus M. Luedi $^{6}$. \\ Joachim Weis ${ }^{7} \cdot$ Emanuel Christ $^{8}$
}

Received: 26 January 2021 / Accepted: 23 March 2021 / Published online: 3 April 2021

(C) The Author(s) 2021

\begin{abstract}
Background Currently, there are no guidelines for neurosurgeons treating patients with Cushing's disease (CD) when intraoperative adenoma identification is negative. Under these circumstances, a total hypophysectomy or hemi-hypophysectomy on the side indicated by inferior petrosal sinus sampling (IPSS) is the approach being used, although there is a subsequent risk of hypopituitarism. Data on whether one-third lateral pituitary gland resection results in cure of hypercortisolism and low rates of hypopituitarism remain inconclusive.

Methods Retrospective single-center study of CD patients with failed intraoperative adenoma identification and subsequent resection of the lateral one-third of the pituitary gland as predicted by IPSS. We assessed (i) histopathological findings, (ii) early and long-term remission rates, and (iii) rates of additional pituitary hormone insufficiency.

Results Ten women and three men met the inclusion criteria. At 3 months, remission was noted in six (46\%) patients: three (23\%) had histologically confirmed adenomas, two (15\%) had ACTH hyperplasia, and one patient (8\%) was positive for Crooke's hyaline degeneration. New pituitary hormone deficits were noted in two patients (15\%). After a median ( \pm SD) follow-up of $14 \pm 4$ years, recurrence was noted in two $(15 \%)$ patients. Long-term control of hypercortisolism was attained by 10 patients ( $77 \%)$, with additional therapies required in nine $(69 \%)$ of them.

Conclusions In CD patients with failed intraoperative adenoma visualization, lateral one-third gland resection resulted in low morbidity and long-term remission in $31 \%$ of patients without the need for additional therapies. Bearing in mind the sample size of this audit, the indication for lateral one-third-gland resection has to be critically appraised and discussed with the patients before surgery.
\end{abstract}

Keywords Cushing's disease $\cdot$ Remission · Adenoma $\cdot$ Petrosal sinus sampling, Pituitary surgery

This article is part of the Topical Collection on Pituitaries

This work has not been previously published.

Lukas Andereggen

lukas.andereggen@gmail.com

1 Department of Neurosurgery, Neurocenter and Regenerative Neuroscience Cluster, Inselspital, Bern University Hospital, University of Bern, Bern, Switzerland

2 Department of Neurosurgery, Kantonsspital Aarau, Aarau, Switzerland

3 Department of Neurosurgery, University Hospital of Basel, Basel, Switzerland
4 Department of Neurosurgery, Medical Center, University of Freiburg, Freiburg, Germany

5 Department of Neuroradiology, Inselspital, Bern University Hospital, University of Bern, Bern, Switzerland

6 Department of Anaesthesiology and Pain Medicine, Inselspital, Bern University Hospital, University of Bern, Bern, Switzerland

7 Institute of Neuropathology, RWTH Aachen University Hospital, Aachen, Germany

8 Department of Endocrinology, Diabetology and Metabolism, University Hospital of Basel, Basel, Switzerland 


\section{Introduction}

Cushing's disease (CD) is the most challenging disorder among hormone-secreting pituitary tumors [13]. CD is predominantly caused by a corticotroph pituitary microadenoma [62]. Despite modified protocols, not infrequently magnetic resonance imaging (MRI) fails to detect adrenocorticotropinsecreting (ACTH) pituitary microadenomas [20, 22, 65]. Thus, bilateral inferior petrosal sinus sampling (IPSS) remains the gold standard in identifying the source of Cushing's syndrome (CS) in patients with negative or equivocal MRI findings $[7,10]$. Nevertheless, subsequent intraoperative exploration still might reveal a pituitary gland with a normal appearance $[7,10]$. Under these circumstances, no commonly accepted treatment guidelines exist, and hemihypophysectomy-or two-thirds gland resection-has been proposed as a valid option, with a subsequent risk of hypopituitarism [19]. Data remain inconclusive with regard to whether one-third resection of the pituitary gland on the side indicated by IPSS results in high remission rates and a low rate of additional pituitary hormone deficiencies.

In this audit of practice, we assessed (i) histopathological findings, (ii) early and long-term remission rates, and (iii) the rate of new pituitary hormone insufficiency in $\mathrm{CD}$ patients with negative MRI findings, failed intraoperative adenoma exploration, and subsequent lateral one-third gland resection on the side indicated by IPSS. Emphasis was placed on assessing the long-term outcome in these patients, given that high long-term recurrence rates are known [11, 49].

\section{Methods}

\section{Study design}

We performed a retrospective study evaluating data from our institutional database, which was prospectively maintained from October 1997 to January 2016. All consecutive patients met clinical and biochemical inclusion criteria for ACTH-dependent CS [27, 34, 64]. Bilateral IPSS was performed due to failed adenoma identification by pituitary MRI. Patients were included if the adenomas could not be identified intraoperatively after careful exploration of the entire gland at the time of transsphenoidal surgery (TSS). Thus, the lateral one-third of the pituitary gland was subsequently resected on the side indicated by IPSS. Tissue was sent to pathology for histological analysis. Early remission rates, hypopituitarism, and long-term outcome were extracted from the medical records.

\section{MR imaging and bilateral IPSS}

PD/T2-weighted, unenhanced, contrast-enhanced, dynamic contrast-enhanced, and post contrast-enhanced overlapping images in three planes over the pituitary region of 1-mm fine-cut images were collected using a 1.5 Tesla MRI $[6,9$, 10]. In patients with negative MRI and ACTH-dependent CS with equivocal responses to biochemical testing (i.e., ovine corticotropin-releasing hormone [oCRH] stimulation and/or high-dose dexamethasone suppression), bilateral IPSS was indicated $[7,10]$. Details of this procedure have been described previously $[7,10]$. In brief, both femoral veins were catheterized. A Hi-Flow Tracker 18 (Renegade Hi-Flow Microcatheter; Boston Scientific Target, Fremont, CA) was placed into each cavernous sinus to enable classification of the venous outflow on both sides. If the cavernous sinus could not be catheterized, the drainage type was recorded based upon an internal carotid artery injection. For venous blood sampling, the microcatheter was retracted distal to the cavernous sinus and placed into each proximal IPS. We determined the venous outflow variances on each side of the IPS after contrast injection and classified them as described by Shiu et al. [61] and Benndorf et al. [12]. An asymmetric IPS was defined as different venous outflow patterns of IPS seen when comparing the left and right sides.

As proposed by Oldfield et al., mean ACTH concentration of both the petrosal sinuses, divided by mean ACTH concentration of a peripheral vein, was indicative of a central ACTH source when gradients were $\geq 2.0$ before and/or $\geq 3.0$ after oCRH stimulation [47]. As for lateralization, mean ACTH concentration of one side of the petrosal sinuses divided by mean ACTH concentration of the other side was positive if gradients were $\geq 1.4[46]$.

\section{Microsurgery}

A transnasal transsphenoidal approach under microscopic magnification was used in all cases [28]. All operations were performed by the senior neurosurgeon (RWS).

As microadenomas can induce limited bulging in the surface of the gland, we created a wide opening in the sellar floor to thoroughly expose the pituitary gland after extensive dural opening. The superior and inferior surfaces of the gland, as well as the lateral walls in direct contact with the medial wall of the cavernous sinus, were explored, and the lateral ligaments were divided, allowing for easier mobilization and inspection of the pituitary gland's lateral surface [30]. If no bulging was noticeable, a vertical incision was made in the lateral gland on the side where the adenoma was suspected to be found, in order to explore the inside of the gland. Suspicious tissue was sent for frozen sectioning. If no adenoma was confirmed, a lateral one-third hypophysectomy was performed using pituitary rongeurs on the side indicated by IPSS (Fig. 1). This included the bottom of the gland in order to maximize the chance of microadenoma removal while minimizing new endocrinopathies $[24,30,31,60$, 


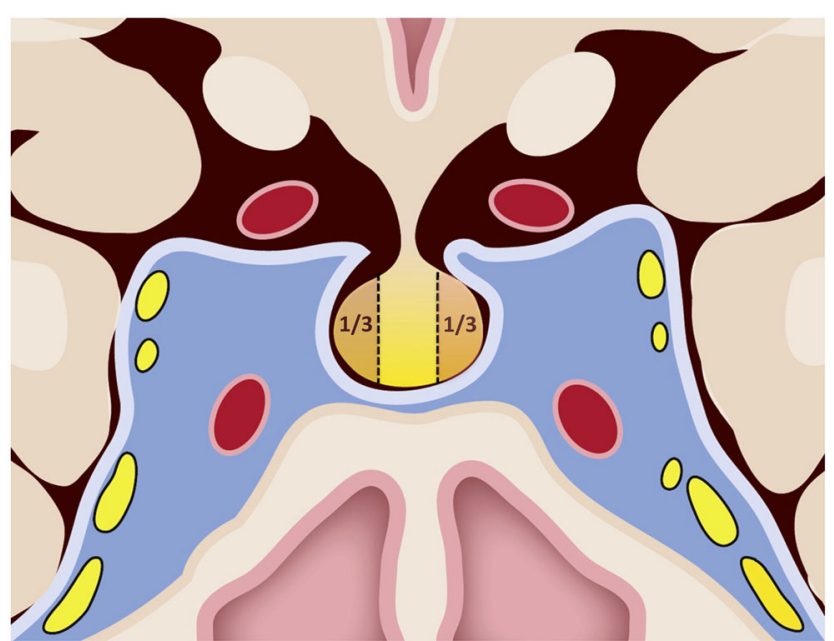

Fig. 1 Coronal view of the pituitary gland and parasellar region with depiction of the surgical technique used. After an extensive opening of the sellar floor followed by cruciate dural opening, the peripheral gland was thoroughly explored and the lateral third (1/3) of the gland periphery was incised on the side indicated by IPSS if no adenoma was found. The tissue (a brownish-yellow color) of the lateral margins adjacent to the medical wall of the cavernous sinus was resected and sent to pathology

63]. Tissue was sent to pathology for histological analysis. To avoid rhinoliquorrhea, the surgical defect was filled with gelatin foam soaked in fibrin glue, and a synthetic absorbable vicryl patch was used to cover the sellar opening $[3-5,8,10,58]$.

\section{Histopathological analyses}

Histopathological analyses were performed to confirm the presence of an ACTH-secreting adenoma. In brief, paraffin sections were stained for hematoxylin, reticulin, and ACTH. In addition, staining was performed for growth hormone, prolactin, thyroid-stimulating hormone, luteinizing hormone, and follicle-stimulating hormone. If no adenoma was found, the tissue was examined for ACTH hyperplasia or positive Crooke's hyalinization as an indirect marker of hypercortisolism [48].

\section{Determination of remission rates}

The early remission rate was determined 3 months postoperatively. Long-term remission rates were extracted $\geq 12$ months postoperatively. Remission was defined as immediate postoperative serum cortisol $<50 \mathrm{nmol} / \mathrm{L}$ and the need for a transitory cortisol replacement therapy. In addition to improvement in the clinical features of CS, remission was defined as normalization of $24 \mathrm{~h}$ urinary cortisol levels, normal salivary cortisol levels for three consecutive days, and/or a normal dexamethasone suppression test during the follow-up visit [27, 41, 64].

\section{Statistical analyses}

Data were analyzed using IBM SPSS statistical software Version 24.0 (IBM Corp., New York, NY, USA) and GraphPad Prism (V7.04 Software, San Diego, CA, USA). Continuous variables were examined for homogeneity of variance and are expressed as mean \pm standard deviation (SD) unless otherwise noted. For comparisons of means between the two groups, Student's $t$-test was used for normally distributed data, and the Mann-Whitney test for nonparametric data. Categorical variables were compared using Pearson's chi-square test or Fisher's exact test, as appropriate. Differences were considered significant at $p<0.05$ for reported two-sided $p$ values.

\section{Results}

\section{Patients' characteristics}

Ten women (77\%) and three men (23\%) met the study inclusion criteria. Patients' characteristics are summarized in Table 1. Median age was 49 \pm 12.4 years (range $24-63$ years). All patients had negative MRI results and underwent IPSS, with the latter predicting a pituitary (central) lesion. Preoperative pituitary deficits were rare. Two patients (15\%) showed isolated one-axis impairment (gonadotrophic deficiency in one patient and thyrotropic deficiency in another patient).

\section{Bilateral IPSS results}

In Supplementary Table 1, classification of the venous outflow and documentation of the venous outflow symmetry are summarized. In addition, central to peripheral ACTH gradients and intersinus gradients (lateralization data) before and after oCRH stimulation are depicted.

In three patients, no data on the drainage pattern were available. Symmetric outflow was recorded in eight patients $(62 \%)$ and asymmetric outflow in two patients (15\%). A central-toperipheral gradient $\geq 2.0$ before oCRH stimulation was attained in 10 patients $(77 \%)$, whereas a gradient $\geq 3.0$ after oCRH stimulation was attained in all of them (100\%). With regard to lateralization, normalized ACTH values (i.e., sideby-side gradients) were not significantly different between patients with a symmetric $(7.3 \pm 2.6)$ or an asymmetric outflow at baseline $(18.2 \pm 13.4 ; p=0.19)$, but they were significantly different after oCRH stimulation (symmetric: $9.0 \pm 4.9$ versus asymmetric: $141.0 \pm 93.9 ; p=0.01)$.

We further noted that ACTH gradients were higher in patients with a histologically confirmed adenoma compared to those without, both before $(19.2 \pm 8.7$ vs. $6.6 \pm 2.6 ; p=0.12)$ and after $(74.8 \pm 43$ vs. $9.6 \pm 5.5, p=0.08)$ oCRH stimulation, 
Table 1 Baseline characteristics and remission rates following lateral one-third-gland resection

\begin{tabular}{lllllll}
\hline Case No. & Age (yrs), sex & IPSS prediction & Histopathology & $\begin{array}{l}\text { Early remission } \\
\text { at 3 months }\end{array}$ & Long-term remission (months) & Additional therapy \\
\hline 1 & $53, \mathrm{~m}$ & Central left & Normal pituitary & No & Yes (203) & Bilateral adrenalectomy \\
2 & $41, \mathrm{f}$ & Central right & ACTH hyperplasia & Yes & Yes (156) & None \\
3 & $49, \mathrm{f}$ & Central left & Adenoma & No & Yes (180) & Bilateral adrenalectomy \\
4 & $40, \mathrm{f}$ & Central right & Adenoma & Yes & Yes (228) & None \\
5 & $52, \mathrm{f}$ & Central left & Adenoma & Yes & No (128) & Drug-treated \\
6 & $37, \mathrm{f}$ & Central right & ACTH hyperplasia & Yes & No (168) & Gamma-knife surgery \\
7 & $50, \mathrm{f}$ & Central right & Adenoma & Yes & Yes (171) & None \\
8 & $63, \mathrm{f}$ & Central left & ACTH hyperplasia & No & Yes (170) & Drug-treated \\
9 & $55, \mathrm{~m}$ & Central right & ACTH hyperplasia & No & Yes (64) & None \\
10 & $60, \mathrm{f}$ & Central right & pos. Crooke hyaline & Yes & Yes (24) & None \\
11 & $35, \mathrm{~m}$ & Central left & Adenoma & No & Yes (98) & Bilateral adrenalectomy \\
12 & $25, \mathrm{f}$ & Central right & pos. Crooke hyaline & No & No (72) & Drug-treated \\
13 & $24, \mathrm{f}$ & Central right & pos. Crooke hyaline & No & Yes (61) & Bilateral adrenalectomy \\
\hline
\end{tabular}

No., number; yrs, years; IPSS, inferior petrosal sinus sampling; $m$, male; $f$, female; $A C T H$, adrenocorticotropic hormone; pos., positive.

but not significantly. In addition, early remission rates were found not to be significantly different in patients with higher ACTH gradients compared to those with lower gradients, both before $(12.2 \pm 5$ vs. $10.8 \pm 6.2, p=0.87)$ and after $(43.1 \pm 38$ vs. $27.4 \pm 12.6 ; p=0.69)$ oCRH stimulation.

\section{Histopathological results}

An ACTH-secreting adenoma was histologically confirmed in five patients (39\%), an ACTH hyperplasia in four (31\%), positive Crooke-hyaline in three patients $(23 \%)$, and a normal pituitary gland in one patient $(7 \%)$.

\section{a Early remission after one-third gland resection}

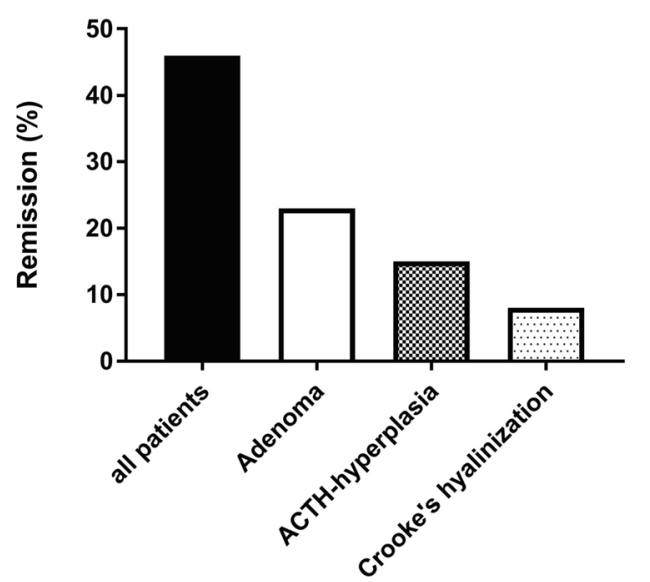

Fig. 2 Early and long-term remission following lateral one-third-gland resection. At early follow-up, remission was noted in six patients (46\%): three patients $(23 \%)$ with histologically confirmed adenomas, two patients (15\%) with ACTH hyperplasia, and one patient (8\%) with positive

\section{Rates of remission}

At 3 months, remission was noted in three patients (23\%) with histologically confirmed adenomas, in two patients $(15 \%)$ with ACTH hyperplasia, and in one patient $(8 \%)$ with positive Crooke's hyaline degeneration (Fig. 2a). When dichotomizing patients into those with confirmed adenoma and those without, we noted early remission in three patients $(60 \%)$ with histologically confirmed adenoma vs. three $(38 \%)$ without $(p=0.59)$.

Recurrence occurred in three patients $(25 \%)$ with initial cortisol normalization. For the long-term control of hypercortisolism, bilateral adrenalectomy was required in four

\section{b Long-term remission after one-third gland resection}

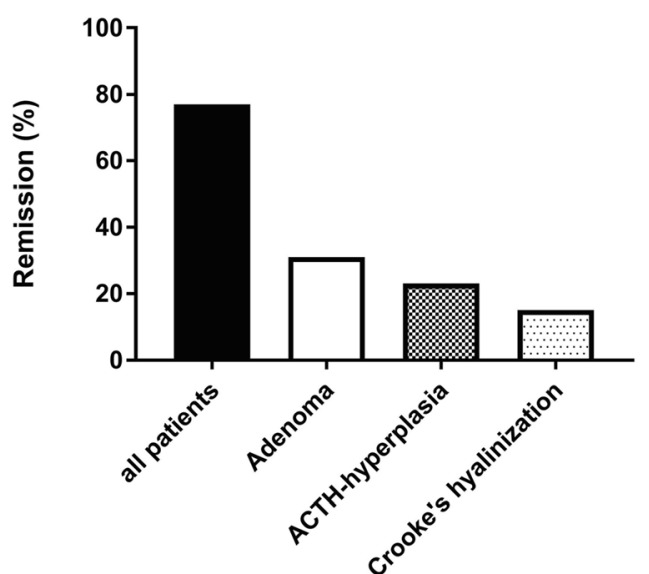

Crooke's hyaline degeneration (a). Long-term remission was noted in 10 patients $(77 \%)$ : four patients $(31 \%)$ with initially confirmed adenoma, three patients $(23 \%)$ with ACTH hyperplasia, two patients $(15 \%)$ with positive Crooke-hyaline, and one patient $(8 \%)$ with negative histology (b) 
patients (33\%), metyrapone therapy in three (25\%), and pituitary radiosurgery in one patient $(8 \%)$ (Table 1).

After a median $( \pm \mathrm{SD})$ follow-up of $14 \pm 4$ years, long-term remission was noted in 10 patients $(77 \%)$ : four $(31 \%)$ with initially confirmed adenoma, three (23\%) with ACTH-hyperplasia, two (15\%) with positive Crooke-hyaline, and one patient $(8 \%)$ with negative histology (Fig. 2b).

\section{Complications of therapeutic interventions}

No mortality due to the surgical intervention was noted. Postoperative complications consisted of rhinoliquorrhea in one patient-requiring temporary lumbar cerebrospinal fluid drain-and transient diabetes insipidus in another patient. New postoperative deficits requiring hormonal replacement were noted in two patients (15\%), with testosterone replacement in one patient and additional growth hormone replacement in a patient with preoperative thyrotropic deficiency. We noted no vascular injuries, meningitis, or abscesses [57].

\section{Discussion}

Our data show that in $\mathrm{CD}$ patients with failed intraoperative adenoma visualization, (i) lateral one-third gland resection resulted in low rates of additional pituitary insufficiencies, but also in low cure rates of hypercortisolism, and (ii) high long-term remission rates ( $>10$ years) can be attained, but only with an interdisciplinary multimodal approach.

$\mathrm{CD}$ is the most challenging disorder among hormonesecreting pituitary tumors $[42,54]$. This has been attributed to difficulty both in the diagnosis and treatment of primarily microadenomas, along with the accuracy of tests in the assessment of endogenous hypercortisolism [7]. TSS is considered the first-line treatment for CD, providing remission in 59-90\% of patients in dedicated tertiary pituitary centers [33]. Thereby, a risk factor for persistent hypercortisolism has been attributed to unsuccessful intraoperative adenoma identification [19, 33, 51]. For these cases, total hypophysectomy or hemi-hypophysectomy has been proposed-but at the expense of hypopituitarism [55]. Our approach resulted in low morbidity and longterm cure in $31 \%$ of patients. Likewise, early remission has been described in $11 \mathrm{CD}$ patients $(38 \%)$ with negative adenoma identification and subsequent hemihypophysectomy [35]. In the other 29 patients $(62 \%)$ of their cohort, additional treatments such as adrenalectomy or radiotherapy were required. However, the authors reported no specific morbidity or rates of associated hypopituitarism [35]. Instead, in patients with two-thirds pituitary gland resection, favorable long-term remission rates were reported in $18(82 \%)$ of the 22 patients and new endocrine deficits requiring hormone replacement in $9 \%$
[19]. While we likewise noted low rates of pituitary insufficiency, we could not attain remission rates as high as those reported by Carr et al. when we limited the resection to the lateral one-third of the pituitary gland [35]. This is of interest given that the rate of histologically confirmed adenomas reported by Carr and colleagues was lower than we noted in our series ( $27 \%$ vs. $38 \%$ in our cohort) [19]. This finding might underscore the hypothesis that unsuccessful histological adenoma confirmation does not seem to be the only predictor of a low remission rate. In fact, failure of histologic confirmation of an ACTH source is an intriguing finding, as remission rates are reported even in the absence of histological adenoma confirmation [67]. Nevertheless, most findings report on a lower initial remission rate and a higher long-term recurrence rate in patients without histological evidence of an adenoma [51]. On the other hand, the higher remission rates reported by Carr et al. might be due to removal of more pituitary tissue, thus increasing the likelihood of removing parts of the adenoma [39]. It is thus conceivable that removing adenohypophyseal corticotroph tissue in the central region of the gland known as the mucoid wedge might increase the chance for long-term cure [39]. Comtois and colleagues reported on 11 patients with absent intraoperative adenoma visualization, in whom a partial hypophysectomy of the central mucoid wedge was performed. This resulted in some remission but significantly lower cure rates as compared to those patients with intraoperative adenoma identification [25]. However, Carr and colleagues also reported that unlike Comtois' observation [25], in their extensive experience with CD microadenomas, tumors were more commonly located in the lateral gland [19]. This underlines the finding that ACTH adenomas were localized in the lateral aspect of the pituitary gland in the majority of cases [37]. Likewise, bilateral IPS sampling in Cushing patients confirms a lateralization in the majority of cases $[19,37]$. In the rare event of negative intraoperative adenoma visualization, the possibility of ectopic ACTH secretion has yet to be considered, despite high sensitivity and specificity attributed to bilateral IPSS [7, 10]. There have been several attempts to improve the predictive value of the intersinus ACTH gradient. In 2012, Mulligan and colleagues demonstrated improved adenoma lateralization using a prolactin-adjusted intersinus ACTH gradient of $>1.4$ in their series [44]. Namely, IPSS prolactin can help to confirm correct catheter placement during venous sampling, thus improving differentiation between $\mathrm{CD}$ and EAS in the absence of proper IPS venous efflux [26, 50, 53]. However, further evaluation of the prolactin-adjusted ACTH ratio is needed to prove reliable surgical guidance [50]. Also, it has been suggested that anatomical variation like intersinus communication might explain sampling 
failures [53]. In our previous work, we noted that IPS asymmetry did not diminish the prediction of the adenoma side [8]. However, the small sample size of this cohort precludes us from undertaking statistical analysis to compare outcome with regard to outflow symmetry. In addition, we have to keep in mind that surgeon experience is of particular importance to guarantee a favorable outcome in the treatment of $\mathrm{CD}[17,36]$.

Given that CD is most commonly caused by a microadenoma, tissue for pathologic diagnosis using standard techniques might be very limited during surgical exploration [29]. While we sent suspicious tissue for frozen sectioning and proceeded with lateral one third hypophysectomy in the case of a negative result, it must be taken into consideration that the reliability of frozen results varies considerably. It has been shown that the addition of intraoperative cytological analyses during surgery provides a useful armamentarium in the diagnosis of CD [52]. In fact, in some cases, the presence of an adenoma can only be proven by cytological preparation, which improves the adenoma identification rate and surgical outcome compared to classical immunostaining methods [38].

Given the similar remission rates attained when limiting the approach to the lateral two-thirds compared to hemihypophysectomy or subtotal hypophysectomy, subtotal resection might be preferred with regard to postoperative pituitary hormone insufficiency, although results remain ambiguous $[17,19]$. As for ACTH-producing adenomas, the risk of postoperative pituitary dysfunction can be higher than for other types of pituitary adenomas, given the need for more extensive intraoperative dissection of the pituitary gland, even in the case of small adenomas [56]. Subtotal hypophysectomy results in new hypopituitarism, with incidence rates ranging from 1 to $35 \%$ [23, 33, 35]. Interestingly, Rees and colleagues noted that the extent of surgical exploration predicted the development of hypopituitarism (88\% total hypophysectomy, $33 \%$ hemi-hypophysectomy, $14 \%$ selective adenomectomy), but not remission (75\% total hypophysectomy, $87 \%$ hemihypophysectomy, $71 \%$ selective adenomectomy) in CD patients [55]. More surprisingly, Yamada et al. reported that none of their 10 patients with hemi-hypophysectomy was noted to have hypopituitarism requiring hormonal replacement [66]. While hormonal insufficiencies vary considerably among studies and are inconsistently reported, it is conceivable that a limited resection results in lower incidences of hormonal disorders following surgery. Thus, our long-term cure rates in $31 \%$ of patients without the need for additional therapies might still be acceptable for the individual patient with regard to the low incidence of new hormonal disorders. However, with a follow-up in excess of 10 years, we noted that high remission rates could be attained when interdisciplinary multimodal therapies were combined with an initial surgical approach. How to treat individual patients after unsuccessful remission should be discussed by neuroendocrinologists and pituitary surgeons in order to develop a proper strategy. We noted the use of metyrapone therapy in up to $25 \%$ of patients for the long-term control of hypercortisolism, an effective approach confirmed by a recent meta-analysis [15]. Alternatively, repeat surgery can be a safe next step prior to radiation or medical therapy in CD patients [18, 59].

These options are mainly indicated in patients with MR-proven sellar lesions, however. In addition, bilateral adrenalectomy-which was required in no less than $33 \%$ of patients in our cohort-has been described as an important option in $\mathrm{CD}$, especially when other treatment options have failed over time [21, 43]. Still, whether negative histology should trigger a different approach with regard to multimodal treatment remains unclear.

To sum up, limiting pituitary gland resection to the lateral one-third is a safe approach with favorable outcome in the face of new endocrine deficits, but remission rates are low.

\section{Study limitations}

The number of patients in our study is relatively small, and statistical uncertainty owing to this small sample size precluded us from undertaking statistical analysis to compare outcome within the subgroups (i.e., adenoma, ACTH hyperplasia, or positive Crooke-hyaline), or with regard to outflow symmetry encountered during IPS. However, it offers reliable insight derived from long-term data obtained over two decades with a follow-up of 14 years.

In contrast to microscopic TSS, an endoscopic approach might be associated with higher gross total tumor removal [40], but results remain ambiguous [2]. In the treatment of $\mathrm{CD}$, there seem to be no clear advantages of a purely endoscopic approach in terms of clinical outcome [1, 16, 45]. In particular, endoscopic surgery for patients with $\mathrm{CD}$ has been shown to have comparable results for microadenomas, with presumably better results for macroadenomas [14], which were not represented in the cohort presented here.

Given the long-term follow-up with recruitment of patients starting as early as 1997, patients were screened with a 1.5 Tesla MRI for the depiction of a microadenoma [6]. While some authors support the use of contrastenhanced 3 Tesla MRI for CD, most of these studies comparing the detection rate of the pituitary 3 Tesla and 1.5 Tesla MRI are using different imaging protocols, thus limiting the diagnostic accuracy of high-field-strength MRI in patients with $C D$ [65]. In particular, a higher magnetic field might not be advantageous in the diagnosis of microadenomas per se [32,65]. 


\section{Conclusions}

In $\mathrm{CD}$ patients with failed intraoperative adenoma visualization, lateral one-third gland resection resulted in low morbidity and long-term remission in $31 \%$ of patients without the need for additional therapies. Bearing in mind the sample size of this audit, the indication for lateral one-third-gland resection has to be critically appraised and discussed with the patients before surgery.

Supplementary Information The online version contains supplementary material available at https://doi.org/10.1007/s00701-021-04830-2.

Acknowledgements The assistance of Ms. Jeannie Wurz in editing the manuscript is greatly appreciated. We express our gratitude to Professor Rolf W. Seiler (RWS), M.D., for granting access to his personal operative recordings. We thank Daniela Miescher for her drawing of the surgical approach used in this disease.

Funding Open access funding provided by Universität Bern.

\section{Declarations}

Competing interests The authors declare no competing interests.

Ethical standards and patient consent The Human Research Ethics Committee of Bern (Kantonale Ethikkommision KEK Bern, Bern, Switzerland) approved the project (KEK $n^{\circ} 10-10-2006$ and 8-112006). The study was performed in accordance with the ethical standards laid down in the 1964 Declaration of Helsinki and its later amendments.

Open Access This article is licensed under a Creative Commons Attribution 4.0 International License, which permits use, sharing, adaptation, distribution and reproduction in any medium or format, as long as you give appropriate credit to the original author(s) and the source, provide a link to the Creative Commons licence, and indicate if changes were made. The images or other third party material in this article are included in the article's Creative Commons licence, unless indicated otherwise in a credit line to the material. If material is not included in the article's Creative Commons licence and your intended use is not permitted by statutory regulation or exceeds the permitted use, you will need to obtain permission directly from the copyright holder. To view a copy of this licence, visit http://creativecommons.org/licenses/by/4.0/.

\section{References}

1. Almutairi RD, Muskens IS, Cote DJ, Dijkman MD, Kavouridis VK, Crocker E, Ghazawi K, Broekman MLD, Smith TR, Mekary RA, Zaidi HA (2018) Gross total resection of pituitary adenomas after endoscopic vs. microscopic transsphenoidal surgery: a metaanalysis. Acta Neurochir 160:1005-1021. https://doi.org/10.1007/ s00701-017-3438-Z

2. Ammirati M, Wei L, Ciric I (2013) Short-term outcome of endoscopic versus microscopic pituitary adenoma surgery: a systematic review and meta-analysis. J Neurol Neurosurg Psychiatry 84:843849. https://doi.org/10.1136/jnnp-2012-303194

3. Andereggen L, Frey J, Andres RH, El-Koussy M, Beck J, Seiler RW, Christ E (2017) 10-year follow-up study comparing primary medical vs. surgical therapy in women with prolactinomas.
Endocrine 55:223-230. https://doi.org/10.1007/s12020-016-11152

4. Andereggen L, Frey J, Andres RH, El-Koussy M, Beck J, Seiler RW, Christ E (2017) Long-term follow-up of primary medical versus surgical treatment of prolactinomas in men: effects on hyperprolactinemia, hypogonadism, and bone health. World Neurosurg 97:595-602. https://doi.org/10.1016/j.wneu.2016.10. 059

5. Andereggen L, Frey J, Andres RH, Luedi MM, Widmer HR, Beck J, Mariani L, Christ E (2021) Persistent bone impairment despite long-term control of hyperprolactinemia and hypogonadism in men and women with prolactinomas. Sci Rep 11:5122. https://doi.org/ 10.1038/s41598-021-84606-x

6. Andereggen L, Frey J, Christ E (2020) Long-term IGF-1 monitoring in prolactinoma patients treated with cabergoline might not be indicated. Endocrine. https://doi.org/10.1007/s12020-020-02557-1

7. Andereggen L, Gralla J, Schroth G, Mordasini P, Andres RH, Widmer HR, Luedi MM, Kellner F, Beck J, Mariani L, Ozdoba C, Christ E (2019) Influence of inferior petrosal sinus drainage symmetry on detection of adenomas in Cushing's syndrome. J Neuroradiol. https://doi.org/10.1016/j.neurad.2019.05.004

8. Andereggen L, Gralla J, Schroth G, Mordasini P, Andres RH, Widmer HR, Luedi MM, Kellner F, Beck J, Mariani L, Ozdoba C, Christ E (2021) Influence of inferior petrosal sinus drainage symmetry on detection of adenomas in Cushing's syndrome. J Neuroradiol 48:10-15. https://doi.org/10.1016/j.neurad.2019.05. 004

9. Andereggen L, Mono ML, Kellner-Weldon F, Christ E (2017) Cluster headache and macroprolactinoma: Case report of a rare, but potential important causality. J Clin Neurosci 40:62-64. https://doi.org/10.1016/j.jocn.2017.01.028

10. Andereggen L, Schroth G, Gralla J, Seiler R, Mariani L, Beck J, Widmer HR, Andres RH, Christ E, Ozdoba C (2012) Selective inferior petrosal sinus sampling without venous outflow diversion in the detection of a pituitary adenoma in Cushing's syndrome. Neuroradiology 54:495-503. https://doi.org/10.1007/s00234-0110915-6

11. Aranda G, Ensenat J, Mora M, Puig-Domingo M, Martinez de Osaba MJ, Casals G, Verger E, Ribalta MT, Hanzu FA, Halperin I (2015) Long-term remission and recurrence rate in a cohort of Cushing's disease: the need for long-term follow-up. Pituitary 18: 142-149. https://doi.org/10.1007/s11102-014-0567-8

12. Benndorf G, Campi A (2002) Aberrant inferior petrosal sinus: unusual transvenous approach to the cavernous sinus. Neuroradiology 44:158-163

13. Braun LT, Rubinstein G, Zopp S, Vogel F, Schmid-Tannwald C, Escudero MP, Honegger J, Ladurner R, Reincke M (2020) Recurrence after pituitary surgery in adult Cushing's disease: a systematic review on diagnosis and treatment. Endocrine 70:218-231. https://doi.org/10.1007/s12020-020-02432-z

14. Broersen LHA, Biermasz NR, van Furth WR, de Vries F, Verstegen MJT, Dekkers OM, Pereira AM (2018) Endoscopic vs. microscopic transsphenoidal surgery for Cushing's disease: a systematic review and meta-analysis. Pituitary 21:524-534. https://doi.org/10.1007/ s11102-018-0893-3

15. Broersen LHA, Jha M, Biermasz NR, Pereira AM, Dekkers OM (2018) Effectiveness of medical treatment for Cushing's syndrome: a systematic review and meta-analysis. Pituitary 21:631-641. https://doi.org/10.1007/s11102-018-0897-z

16. Broersen LHA, van Haalen FM, Biermasz NR, Lobatto DJ, Verstegen MJT, van Furth WR, Dekkers OM, Pereira AM (2019) Microscopic versus endoscopic transsphenoidal surgery in the Leiden cohort treated for Cushing's disease: surgical outcome, mortality, and complications. Orphanet J Rare Dis 14:64. https://doi. org/10.1186/s13023-019-1038-0 
17. Bunevicius A, Laws ER, Vance ML, Iuliano S, Sheehan J (2019) Surgical and radiosurgical treatment strategies for Cushing's disease. J Neuro-Oncol 145:403-413. https://doi.org/10.1007/ s11060-019-03325-6

18. Burke WT, Penn DL, Repetti CS, Iuliano S, Laws ER (2019) Outcomes after repeat transsphenoidal surgery for recurrent cushing disease: updated. Neurosurgery. https://doi.org/10.1093/neuros/ nyz193

19. Carr SB, Kleinschmidt-DeMasters BK, Kerr JM, KiseljakVassiliades K, Wierman ME, Lillehei KO (2018) Negative surgical exploration in patients with Cushing's disease: benefit of two-thirds gland resection on remission rate and a review of the literature. $\mathrm{J}$ Neurosurg 129:1260-1267. https://doi.org/10.3171/2017.5. JNS162901

20. Cebula H, Baussart B, Villa C, Assie G, Boulin A, Foubert L, Aldea S, Bennis S, Bernier M, Proust F, Gaillard S (2017) Efficacy of endoscopic endonasal transsphenoidal surgery for Cushing's disease in 230 patients with positive and negative MRI. Acta Neurochir 159:1227-1236. https://doi.org/10.1007/s00701-0173140-1

21. Chiloiro S, Giampietro A, Raffaelli M, D'Amato G, Bima C, Lauretti L, Anile C, Lombardi CP, Rindi G, Bellantone R, De Marinis L, Pontecorvi A, Bianchi A (2019) Synchronous bilateral adrenalectomy in ACTH-dependent hypercortisolism: predictors, biomarkers and outcomes. Endocrine 66:642-649. https://doi.org/ 10.1007/s12020-019-02091-9

22. Chittiboina P, Talagala SL, Merkle H, Sarlls JE, Montgomery BK, Piazza MG, Scott G, Ray-Chaudhury A, Lonser RR, Oldfield EH, Koretsky AP, Butman JA (2016) Endosphenoidal coil for intraoperative magnetic resonance imaging of the pituitary gland during transsphenoidal surgery. J Neurosurg 125:1451-1459. https://doi. org/10.3171/2015.11.JNS151465

23. Ciric I, Ragin A, Baumgartner C, Pierce D (1997) Complications of transsphenoidal surgery: results of a national survey, review of the literature, and personal experience. Neurosurgery 40:225-236; discussion 236-227. https://doi.org/10.1097/00006123-19970200000001

24. Cohen-Cohen S, Gardner PA, Alves-Belo JT, Truong HQ, Snyderman CH, Wang EW, Fernandez-Miranda JC (2018) The medial wall of the cavernous sinus. Part 2: Selective medial wall resection in 50 pituitary adenoma patients. J Neurosurg 131:131140. https://doi.org/10.3171/2018.5.JNS18595

25. Comtois R, Beauregard H, Hardy J, Robert F, Somma M (1993) High prolactin levels in patients with Cushing's disease without pathological evidence of pituitary adenoma. Clin Endocrinol 38: 601-607. https://doi.org/10.1111/j.1365-2265.1993.tb02141.x

26. De Sousa SMC, McCormack AI, McGrath S, Torpy DJ (2017) Prolactin correction for adequacy of petrosal sinus cannulation may diminish diagnostic accuracy in Cushing's disease. Clin Endocrinol 87:515-522. https://doi.org/10.1111/cen.13401

27. Dichek HL, Nieman LK, Oldfield EH, Pass HI, Malley JD, Cutler GB Jr (1994) A comparison of the standard high dose dexamethasone suppression test and the overnight 8-mg dexamethasone suppression test for the differential diagnosis of adrenocorticotropindependent Cushing's syndrome. J Clin Endocrinol Metab 78:418422. https://doi.org/10.1210/jcem.78.2.8106630

28. Donofrio CA, Losa M, Gemma M, Giudice L, Barzaghi LR, Mortini P (2017) Safety of transsphenoidal microsurgical approach in patients with an ACTH-secreting pituitary adenoma. Endocrine 58:303-311. https://doi.org/10.1007/s12020-016-1214-0

29. Erfe JM, Perry A, McClaskey J, Inzucchi SE, James WS, Eid T, Bronen RA, Mahajan A, Huttner A, Santos F, Spencer D (2018) Long-term outcomes of tissue-based ACTH-antibody assay-guided transsphenoidal resection of pituitary adenomas in Cushing disease. J Neurosurg 129:629-641. https://doi.org/10.3171/2017.3. JNS162245
30. Fernandez-Miranda JC, Gardner PA, Rastelli MM Jr, Peris-Celda M, Koutourousiou M, Peace D, Snyderman CH, Rhoton AL Jr (2014) Endoscopic endonasal transcavernous posterior clinoidectomy with interdural pituitary transposition. J Neurosurg 121:91-99. https://doi.org/10.3171/2014.3.JNS131865

31. Fernandez-Miranda JC, Zwagerman NT, Abhinav K, Lieber S, Wang EW, Snyderman CH, Gardner PA (2018) Cavernous sinus compartments from the endoscopic endonasal approach: anatomical considerations and surgical relevance to adenoma surgery. J Neurosurg 129:430-441. https://doi.org/10.3171/2017.2. JNS162214

32. Fukuhara N, Inoshita N, Yamaguchi-Okada M, Tatsushima K, Takeshita A, Ito J, Takeuchi Y, Yamada S, Nishioka H (2019) Outcomes of three-Tesla magnetic resonance imaging for the identification of pituitary adenoma in patients with Cushing's disease. Endocr J 66:259-264. https://doi.org/10.1507/endocrj.EJ18-0458

33. Hammer GD, Tyrrell JB, Lamborn KR, Applebury CB, Hannegan ET, Bell S, Rahl R, Lu A, Wilson CB (2004) Transsphenoidal microsurgery for Cushing's disease: initial outcome and long-term results. J Clin Endocrinol Metab 89:6348-6357. https://doi.org/10. 1210/jc.2003-032180

34. Hirsch D, Shimon I, Manisterski Y, Aviran-Barak N, Amitai O, Nadler V, Alboim S, Kopel V, Tsvetov G (2018) Cushing's syndrome: comparison between Cushing's disease and adrenal Cushing's. Endocrine 62:712-720. https://doi.org/10.1007/ s12020-018-1709-y

35. Hofmann BM, Hlavac M, Martinez R, Buchfelder M, Muller OA, Fahlbusch R (2008) Long-term results after microsurgery for Cushing disease: experience with 426 primary operations over 35 years. J Neurosurg 108:9-18. https://doi.org/10.3171/JNS/2008/ 108/01/0009

36. Honegger J, Grimm F (2018) The experience with transsphenoidal surgery and its importance to outcomes. Pituitary 21:545-555. https://doi.org/10.1007/s11102-018-0904-4

37. Invitti C, Pecori Giraldi F, de Martin M, Cavagnini F (1999) Diagnosis and management of Cushing's syndrome: results of an Italian multicentre study. Study Group of the Italian Society of Endocrinology on the Pathophysiology of the HypothalamicPituitary-Adrenal Axis. J Clin Endocrinol Metab 84:440-448. https://doi.org/10.1210/jcem.84.2.5465

38. Kurosaki M, Luedecke DK, Knappe UJ, Flitsch J, Saeger W (2000) The value of intraoperative cytology during transsphenoidal surgery for ACTH-secreting microadenoma. Acta Neurochir 142: 865-870. https://doi.org/10.1007/s007010070071

39. La Rosa S, Uccella S, Dainese L, Marchet S, Placidi C, Vigetti D, Capella C (2008) Characterization of c-kit (CD117) expression in human normal pituitary cells and pituitary adenomas. Endocr Pathol 19:104-111. https://doi.org/10.1007/s12022-008-9032-4

40. Li A, Liu W, Cao P, Zheng Y, Bu Z, Zhou T (2017) Endoscopic versus microscopic transsphenoidal surgery in the treatment of pituitary adenoma: a systematic review and meta-analysis. World Neurosurg 101:236-246. https://doi.org/10.1016/j.wneu.2017.01. 022

41. Mayberg M, Reintjes S, Patel A, Moloney K, Mercado J, Carlson A, Scanlan J, Broyles F (2018) Dynamics of postoperative serum cortisol after transsphenoidal surgery for Cushing's disease: implications for immediate reoperation and remission. J Neurosurg 129: 1268-1277. https://doi.org/10.3171/2017.6.JNS17635

42. Molitch ME (2017) Diagnosis and treatment of pituitary adenomas: a review. JAMA 317:516-524. https://doi.org/10.1001/jama.2016. 19699

43. Morelli V, Minelli L, Eller-Vainicher C, Palmieri S, Cairoli E, Spada A, Arosio M, Chiodini I (2018) Predictability of hypoadrenalism occurrence and duration after adrenalectomy for ACTH-independent hypercortisolism. J Endocrinol Investig 41: 485-493. https://doi.org/10.1007/s40618-017-0788-6 
44. Mulligan GB, Faiman C, Gupta M, Kennedy L, Hatipoglu B, Hui F, Weil RJ, Hamrahian AH (2012) Prolactin measurement during inferior petrosal sinus sampling improves the localization of pituitary adenomas in Cushing's disease. Clin Endocrinol 77:268-274. https://doi.org/10.1111/j.1365-2265.2012.04339.x

45. Muskens IS, Briceno V, Ouwehand TL, Castlen JP, Gormley WB, Aglio LS, Zamanipoor Najafabadi AH, van Furth WR, Smith TR, Mekary RA, Broekman MLD (2018) The endoscopic endonasal approach is not superior to the microscopic transcranial approach for anterior skull base meningiomas-a meta-analysis. Acta Neurochir 160:59-75. https://doi.org/10.1007/s00701-017-3390-y

46. Oldfield EH, Chrousos GP, Schulte HM, Schaaf M, McKeever PE, Krudy AG, Cutler GB Jr, Loriaux DL, Doppman JL (1985) Preoperative lateralization of ACTH-secreting pituitary microadenomas by bilateral and simultaneous inferior petrosal venous sinus sampling. N Engl J Med 312:100-103

47. Oldfield EH, Doppman JL, Nieman LK, Chrousos GP, Miller DL, Katz DA, Cutler GB Jr, Loriaux DL (1991) Petrosal sinus sampling with and without corticotropin-releasing hormone for the differential diagnosis of Cushing's syndrome. N Engl J Med 325:897-905

48. Oldfield EH, Vance ML, Louis RG, Pledger CL, Jane JA Jr, Lopes MB (2015) Crooke's changes in Cushing's syndrome depends on degree of hypercortisolism and individual susceptibility. J Clin Endocrinol Metab 100:3165-3171. https://doi.org/10.1210/JC. 2015-2493

49. Pendharkar AV, Sussman ES, Ho AL, Hayden Gephart MG, Katznelson L (2015) Cushing's disease: predicting long-term remission after surgical treatment. Neurosurg Focus 38:E13. https:// doi.org/10.3171/2014.10.FOCUS14682

50. Perlman JE, Johnston PC, Hui F, Mulligan G, Weil RJ, Recinos PF, Yogi-Morren D, Salvatori R, Mukherjee D, Gallia G, Kennedy L, Hamrahian AH (2021) Pitfalls In performing and interpreting inferior petrosal sinus sampling: personal experience and literature review. J Clin Endocrinol Metab. https://doi.org/10.1210/clinem/ dgab012

51. Pouratian N, Prevedello DM, Jagannathan J, Lopes MB, Vance ML, Laws ER Jr (2007) Outcomes and management of patients with Cushing's disease without pathological confirmation of tumor resection after transsphenoidal surgery. J Clin Endocrinol Metab 92:3383-3388. https://doi.org/10.1210/jc.2007-0208

52. Qiao N, Swearingen B, Hedley-Whyte ET, Tritos NA (2019) The utility of intraoperative cytological smear and frozen section in the surgical management of patients with Cushing's disease due to pituitary microadenomas. Endocr Pathol 30:180-188. https://doi. org/10.1007/s12022-019-09582-5

53. Qiao X, Ye H, Zhang X, Zhao W, Zhang S, Lu B, Wang X, Zhang Z, Wu X, He M, Zhao X, Li S, Zhou L, Yang Y, Hu R, Li Y (2015) The value of prolactin in inferior petrosal sinus sampling with desmopressin stimulation in Cushing's disease. Endocrine 48: 644-652. https://doi.org/10.1007/s12020-014-0338-3

54. Ragnarsson O, Olsson DS, Papakokkinou E, Chantzichristos D, Dahlqvist P, Segerstedt E, Olsson T, Petersson M, Berinder K, Bensing S, Hoybye C, Eden-Engstrom B, Burman P, Bonelli L, Follin C, Petranek D, Erfurth EM, Wahlberg J, Ekman B, Akerman AK, Schwarcz E, Bryngelsson IL, Johannsson G (2019) Overall and disease-specific mortality in patients with Cushing disease: a Swedish nationwide study. J Clin Endocrinol Metab 104: 2375-2384. https://doi.org/10.1210/jc.2018-02524

55. Rees DA, Hanna FW, Davies JS, Mills RG, Vafidis J, Scanlon MF (2002) Long-term follow-up results of transsphenoidal surgery for Cushing's disease in a single centre using strict criteria for remission. Clin Endocrinol 56:541-551
56. Roelfsema F, Biermasz NR, Pereira AM (2012) Clinical factors involved in the recurrence of pituitary adenomas after surgical remission: a structured review and meta-analysis. Pituitary 15:71-83. https://doi.org/10.1007/s11102-011-0347-7

57. Schuss P, Hadjiathanasiou A, Klingmuller D, Guresir A, Vatter H, Guresir E (2018) Transsphenoidal pituitary surgery: comparison of two sellar reconstruction techniques and their effect on postoperative cerebrospinal fluid leakage. Neurosurg Rev 41:1053-1058. https://doi.org/10.1007/s10143-018-0949-x

58. Seiler RW, Mariani L (2000) Sellar reconstruction with resorbable vicryl patches, gelatin foam, and fibrin glue in transsphenoidal surgery: a 10-year experience with 376 patients. J Neurosurg 93:762765. https://doi.org/10.3171/jns.2000.93.5.0762

59. Serban AL, Del Sindaco G, Sala E, Carosi G, Indirli R, Rodari G, Giavoli C, Locatelli M, Carrabba G, Bertani G, Marfia G, Mantovani G, Arosio M, Ferrante E (2019) Determinants of outcome of transsphenoidal surgery for Cushing disease in a singlecentre series. J Endocrinol Investig. https://doi.org/10.1007/ s40618-019-01151-1

60. Shin SS, Gardner PA, Ng J, Faraji AH, Agarwal N, Chivukula S, Fernandez-Miranda JC, Snyderman CH, Challinor SM (2017) Endoscopic endonasal approach for adrenocorticotropic hormonesecreting pituitary adenomas: outcomes and analysis of remission rates and tumor biochemical activity with respect to tumor invasiveness. World Neurosurg 102:651-658 e651. https://doi.org/10.1016/ j.wneu.2015.07.065

61. Shiu PC, Hanafee WN, Wilson GH, Rand RW (1968) Cavernous sinus venography. Am J Roentgenol Radium Therapy, Nucl Med 104:57-62

62. Tritos NA, Biller BM, Swearingen B (2011) Management of Cushing disease. Nat Rev Endocrinol 7:279-289. https://doi.org/ 10.1038/nrendo.2011.12

63. Truong HQ, Lieber S, Najera E, Alves-Belo JT, Gardner PA, Fernandez-Miranda JC (2018) The medial wall of the cavernous sinus. Part 1: Surgical anatomy, ligaments, and surgical technique for its mobilization and/or resection. J Neurosurg 131:122-130. https://doi.org/10.3171/2018.3.JNS18596

64. Valassi E, Franz H, Brue T, Feelders RA, Netea-Maier R, Tsagarakis S, Webb SM, Yaneva M, Reincke M, Droste M, Komerdus I, Maiter D, Kastelan D, Chanson P, Pfeifer M, Strasburger CJ, Toth M, Chabre O, Tabarin A, Krsek M, Fajardo C, Bolanowski M, Santos A, Wass JAH, Trainer PJ, Group ES (2017) Diagnostic tests for Cushing's syndrome differ from published guidelines: data from ERCUSYN. Eur J Endocrinol 176: 613-624. https://doi.org/10.1530/EJE-16-0967

65. Vitale G, Tortora F, Baldelli R, Cocchiara F, Paragliola RM, Sbardella E, Simeoli C, Caranci F, Pivonello R, Colao A, Group ABC (2017) Pituitary magnetic resonance imaging in Cushing's disease. Endocrine 55:691-696. https://doi.org/10.1007/s12020016-1038-y

66. Yamada S, Fukuhara N, Nishioka H, Takeshita A, Inoshita N, Ito J, Takeuchi Y (2012) Surgical management and outcomes in patients with Cushing disease with negative pituitary magnetic resonance imaging. World Neurosurg 77:525-532. https://doi.org/10.1016/j. wneu.2011.06.033

67. Yap LB, Turner HE, Adams CB, Wass JA (2002) Undetectable postoperative cortisol does not always predict long-term remission in Cushing's disease: a single centre audit. Clin Endocrinol 56:2531

Publisher's note Springer Nature remains neutral with regard to jurisdictional claims in published maps and institutional affiliations. 